\title{
Diş Hekimliğinde Fitoterapinin Yeri
}

\author{
The Phytotherapy in Dentistry
}

\author{
Hazal ÖZER ${ }^{1}$ (D) \\ hazal0713ozer@gmail.com
}

\author{
Merve ABAKLI İNCI ${ }^{1}$ (D) \\ merveabakli@gmail.com
}

\author{
Hemra Nur ÖZAȘIK ${ }^{* 1}$ (D \\ dthemranur@gmail.com
}

\begin{abstract}
öz
Fitoterapi, hastalıklardan korunmak ve tedaviyi desteklemek amacıyla bitkisel ekstrelerden yararlanılan bir tedavi biçimidir. Eski çağlardan beri hep merak konusu olan bitkilerin özellikle de şifa amaçlı çokça kullanıldığı bilinmektedir. Günümüzde çeșitli hastalıkların tedavisinde kullanılan birç̧ok medikal ilacın kökenini bitkiler olușturmaktadır. Mevcut ilaçların, tedavi yöntemlerinin kronik hastalıkları tedavi etmedeki yetersizliği hem hastaları hem de sağlık profesyonellerini alternatif tedavi arayışlarına yöneltmektedir. Bunlara ek olarak bitkisel ekstrelerin konvansiyonel ilaçlara göre yan etkilerinin daha az olması, ekonomik, ulaşılabilir olmaları modern tıp tedavilerinde kullanımlarını yaygınlaştırmıştır.

Diș hekimliğinde fitoterapiden bitkisel ekstrelerin sağladı $\breve{ı}$ antimikrobiyal, antiinflamatuar, sedatif ve anksiyolitik etkiler nedeniyle sıkça yararlanılmaktadır. Ağız yaraları, halitozis ve diş eti hastalıklarının tedavisinde bitkisel ektrelerin antimikrobiyal ve antiinflamatuar etkilerinden yararlanılarak gargaralar kullanılabilir. Piyasadaki mevcut gargaralarla karşılaștırıldığında oldukça başarılı bulunan bu gargaralar; renklenme, tat hassasiyeti, acı tat gibi yan etkilerinin de olmaması nedeniyle bitkisel kaynaklara olan ilgiyi daha da artırmıştır. Bitkisel ekstrelerin antikaryojenik etkileri sayesinde çürük oluşumu önlenebilir, ağız ve diş sağlığı korunabilir. Kök kanal tedavisi uygulamalarında irigasyon ajanı, kanal içi medikament olarak kullanılabilen bitkisel ektreler faydalı bulunmuştur. Bunlara ek olarak fitoterapiden; cerrahi uygulamalarda kanama durdurucu, yara iyileşmesini hızlandırıcı etkilerle yararlanılabilir.

Bu derleme kapsamında ağız ve diş sağlığı alanında kullanılan bitkiler ve bu bitkilerin dental tedavilerdeki yeri hakkında bilgi verilmesi amaçlanmıştır.
\end{abstract}

Anahtar Kelimeler: Bitkisel terapi, Bitkiler, Diş hekimliği, Fitoterapi

$\begin{array}{lll}\text { Geliş: } 08.09 .2021 & \text { Kabul: } 17.10 .2021 & \text { Yayın: 29.12.2021 }\end{array}$

\begin{abstract}
Phytotherapy is a form of treatment that uses herbal extracts prevent diseases, support treatment. It is known plants, which have always been a matter of curiosity since ancient times, especially for healing purposes. Plants are now the source of many medical drugs used to treat a variety of diseases. Due to the inadequacy of current drugs and treatment methods for chronic diseases, both patients and health professionals are looking for alternative treatments. In addition, fact herbal extracts have less side effects compared conventional drugs, are affordable, accessible have made use widespread in modern medical treatments.

Phytotherapy is frequently used because of antimicrobial, anti-inflammatory, sedative, anxiolytic effects provided herbal extracts. In treatment mouth sores, halitosis, gum diseases, mouthwashes can be used by taking advantage of antimicrobial, anti-inflammatory effects herbal extracts. These mouthwashes are successful when compared to existing mouthwashes on the market; due to the absence of side effects such as coloration and taste sensitivity, the interest in herbal sources has grown even more. Thanks to anticariogenic effects of herbal extracts, caries formation can be prevented, dental health can be protected. Herbal extracts, which can be used irrigation agents, intracanal medicaments, have been found useful root canal treatment applications. In addition these, surgical applications, it can be used with bleeding-stopping, wound healing effects.
\end{abstract}

Keywords: Herbal therapy, Plants, Dentistry, Phytotherapy

$\begin{array}{lll}\text { Received: 08.09.2021 Accepted: } 17.10 .2021 & \text { Published: } 29.12 .2021\end{array}$

Atıf / Citation: Özer H, Abaklı İnci M, Özaşık HN. Diş hekimliğinde fitoterapinin yeri. NEU Dent J. 2021;3:128-33. 


\section{Gíriş}

Fitoterapi; tedaviye yardımcı olmak veya hastalıkları önlemek amacı ile bitkilerden ve onların etkili kısımlarından faydalanılarak uygulanan tedavi şeklidir. ${ }^{1}$ Fitoterapi teriminin ilk kez 1870-1953 yılları arasında yaşamış Fransız hekim Henri Lenclerc tarafından La Presce Medical adlı dergide kullanıldığı bilinmektedir. ${ }^{2}$ Ancak bitkiler bu tarihten öncesinde de farklı kültürler tarafından tedavi amaçlı kullanılmıştır. WHO'ya göre, dünya nüfusunun $\% 80$ 'ininde, özellikle de gelişmekte olan ülkelerde reçete edilen ilaçlarda bitkilerden faydanılmaktadır. ${ }^{3}$ Bitkisel kaynaklardan elde edilen ilaçların konvansiyonel ilaçlara göre daha az yan etkisi olması sebebiyle; fitoterapi modern tıpta önemli bir yerde bulunmaktadır. ${ }^{4}$ Diş hekimliğinde bitkisel ekstreler antiinflamatuar, antimikrobiyal, sedatif, analjezik ve antikoagülan etkileri nedeniyle sıkça kullanılmaktadır.

\section{Antiinflamatuar Etki}

Bitkisel ajanlar pulpal iltihabın tedavisinde, dișeti iltihabının giderilmesinde, oral hijyenin sağlanılmasında kullanılmaktadır. Propolis, arıların bitki tomurcuklarından toplanılan, yapışkan ve reçinemsi bir maddedir. ${ }^{4}$ İçeriğinde bulunan flavanoidler; reçinenin büyük bir kısmını oluşturur ve propolisin aktif kismindan sorumludur. Bu sayede antiinflamatuar, antibakteriyel, antiviral, antikaryojenik özellikleri vardir. $^{5}$

2010 yılında yapılan bir çalışmada propolisin pulpa dokusu üzerindeki etkileri araştırılmış; bu amaçla da dental tedavilerde rutin olarak kullanılan mineral trioksit agregat (MTA) ve kalsiyum hidroksit $\left(\mathrm{CaOH}_{2}\right)$ ile karşılaştırılmıştır. $\mathrm{CaOH}_{2}$ ile tedavi edilen dişlerde 15. günde ve 45. günde propolis ve MTA'ya göre daha fazla pulpa iltihabı gözlemlenmiștir. Ayrıca propolis ve MTA'da daha fazla dentin köprüsü oluşumu izlenmiștir. $^{6}$

Supragingival plak ve dişeti iltihabının kontrol edilmesinde etkili olduğu kanıtlanan bitkisel ekstrelerden ağız gargaralarının hazırlanmasında da yararlanılmıştır. Pistorius ve ark. S. officinalis, M. piperita, mentol, M. chamomilla, C. myrrha, Carum carvi (Umbelliferae), Eugenia caryophyllus (Myrtaceae) ve E. purpurea içeren bitkisel bazlı gargaraların plak indeksinde anlamlı bir azalmaya sebep olduğunu bildirmişlerdir. Buna bağlı olarak periodontal hastalığı olan hastalarda dişeti iltihabını azaltması amacıyla günlük olarak kullanılabileceği sonucuna varılmiştır.

\section{Antimikrobiyal Aktivite}

Bitkilerin antimikrobiyal etkileri genellikle; plazma membranı veya mikroorganizmaların yapısal enzimleri üzerinde etkili olan fenol, saponin ve fla- vonoidler gibi bileşiklerle sağlanmaktadır. ${ }^{8}$ Kandidal enfeksiyonlarda sıkça kullanılan nistatinin; döküntü, bulantı, ishal, kusma ve epigastrik ağrı gibi semptomlara yol açması alternatif ilaç arayıșına yol açmıştır. Ayrıca nistatin gargarasının acı tadını azaltmak amacıyla eklenen tatlandırıcıların çürüğe neden olduğu bilinmektedir. ${ }^{9}$ Khorram ve ark. yaptıkları çalışmada nistatin, rezene ve kimyonun antifungal etkilerini karşılaştırmışlardır. Çalışma sonunda nistatin en küçük konsantrasyonda en yüksek antifungal etkiye sahip bulunmuştur. Rezene ve kimyon arasında istatistiksel olarak anlamlı bir fark bulunmamıştır ancak geleneksel ilaçlara alternatif olarak umut vaat ettikleri bildirilmiştir. ${ }^{10}$

Noumi ve ark. S. persica köklerinden elde edilmiş $300 \mathrm{mg} / \mathrm{ml}$ yoğunluktraki ekstrenin Candida albicans, Candida glabrata, Candida parapsilosis 'e karşı antifungal etkisini gözlemlemişlerdir. Bu antimikotik etkinin misvağın kök kısmında bulunan klor, trimetilamin, alkaloid rezin ve sülfür içeriğine bağlı olduğu düşünülmektedir. Klinik olarak izole edilen Candida albicans, Candida tropicalis, Candida krusei, Candida guilliermondii, Candida dubliniensis ve Candida glabrata üzerinde agar difüzyon testi ile yapılan bir çalışmada katı ve toz haline getirilmiş misvak kullanılmıştır. Katı misvak kullanılan grupta tüm kandida türlerinde güçlü antifungal etki gözlenirken, toz halindeki misvağın kullanıldığı grupta hiçbir antifungal etki tespit edilememiştir. ${ }^{11}$

Ağız gargaraları subgingival ve supragingival biyofilmin azaltılmasında, periodontal hastalıkların tedavisinde, oral hijyenin sağlanmasında sıkça kullanılmaktadır. Klorheksidin diglukonatın (CHX) tadının acı olması, tat hassasiyeti ve renklenmeye sebep olması alternatif materyal arayışına neden olmuștur. ${ }^{12}$

Kamath ve ark. CHX, çay ağacı yağı ve aloe vera'nın yüksek çürük riskli okul çocuklarında antimikrobiyal etkilerini karşılaştırmışlardır. Çalışma sonucunda aloe vera ve çay ağacı yağı; CHX kadar plak ve diş eti iltihabının kontrolünde etkili bulunmuştur. ${ }^{13}$

Kronik periodontitisli hastalarda Porphyromonas gingivalis'e karşı etkilerini değerlendirmek amacıyla minosiklin, köri yaprağı ve propolis karşılaş̧tırılmıştır. Propolis ile tedavi edilen grupta hem klinik ataçman seviyesi (CAL) hem de sondlama derinliğin (PPD)' de iyileşme gözlenmiştir. Minosiklin ile tedavi olan grupta ise PPD' de azalma gözlemlenirken CAL kazancı gözlenmemiştir. Köri yaprağı ile tedavi olan grupta ise anlamlı bir iyileşme gözlenmemiștir. ${ }^{14}$

Triphala ağız gargarası Streptococcus mutans (S. mutans) üzerinde oldukça antibakteriyel etkilere sahiptir. ${ }^{15}$ Triphala ve CHX antiplak etkileri karşılaştırıldığında aralarında istatistiksel olarak anlamlı bir fark bulunamazken; Triphala CHX'e kıyasla potansiyel 
yan etki içermeden başarılı sonuçlar göstermiştir. ${ }^{16}$ Propolisin özellikle Staphylococcus auerus'a karşı güçlü antibakteriyel etkisi olduğu yapılan çalıșmalarda gözlenmiștir. ${ }^{17}$

Çay, diş çürügünü önlemede bakterisidal ve bakteriyostatik etkiye sahip kateșin ve tanen gibi bileșikler içermektedir. 2019 yılında yapılan in vivo bir çalıșmada yeșil çay, siyah çay ve Listerin'in S. Mutans üzerindeki antibakteriyel etkisi karşılaştııılmıștır. Çalışmanın sonucunda istatistiksel olarak en etkili gargaranın yeşil çay olduğu bildirilmiștir. ${ }^{18}$

Euphorbiacae bitkisinin (Hint yağı) temel parçalarından risinoleik asitin, diș minesi üzerinde oluşturulan yapay çürüklerde S. mutans 'ın üremesini önlediği gösterilmiștir. ${ }^{19}$ Sanguinaria canadensis (Papaveraceae-kan otu) içeren gargara ve diș macunları yapılan çalışmalarda white-spot lezyonların remineralizasyonunda başarılı bulunmuştur. ${ }^{20}$

Terminila chebula (Kara halile) antioksidan özellikte, birçok oral patojene karşı antibakteriyel etkinlik göstermektedir. ${ }^{21}$ Mali ve ark. tarafından yapılan çalışmada süt dişlerinde formokrezol, Therminila chebula jeli ve Myristica frangs jeli pulpotomi tedavilerinde karşılaștırılmıştır. 12 aylık klinik ve radyografik takip sonucunda istatistiksel olarak anlamlı bir fark bulunmamıștır. ${ }^{22}$

\section{Sedatif ve Anksiyolitik Etkiler}

Bitkilerin analjezik, antispazmik ve yatıştırıcı özelliklerinin olduğu yapılan birçok çalışmada gösterilmiştir. Matricaria Chamomile (papatya) analjezik ve yatıştırıcı özellikleri nedeniyle yaygın olarak kullanılmaktadır. Papatya ayrıca ağız ve dișeti yaralanmaları ve küçük enfeksiyonları tedavi etmek için gargara olarak da kullanılmaktadır. ${ }^{23}$ Kedi otu köklerinin önemli parçaları olan valerenik, izo-valerenik ve valepotriate asit sakinleștirici ve anksiyolitik etkilere sahiptir. ${ }^{24}$ Bazı araştırmacılar mandibular üçüncü molar ameliyatından bir saat önce verilen 100 mg'lık kedi otunun endișeyi azalttı̆̆ını gözlemlemișlerdir. Bu etkinin 5 mg'lık diazepam ile karşılaștırılabilecek düzeyde olduğu belirtilmiștir. ${ }^{25}$

\section{Endodontik Ajanlar}

Kök kanal tedavisinin başarısı; mekanik preparasyona, irigasyona ve kök kanallarının sızdırmaz bir şekilde doldurulmasına bağlıdır. Nekrotik dokular, pulpa artıkları, mikroorganizmalardan oluşan yapının uzaklaștırılmasında irigasyon önemli role sahiptir.

Kök kanal tedavilerinde irrigasyon amaciyla sodyum hipoklorit ( $\mathrm{NaOCl})$ sıkça kullanılmakta olup; doku toksisitesi, alerjik reaksiyonlar, dentin yapısı üzerindeki olumsuz etkileri ve smear tabakasını kaldıramaması gibi dezavantajları nedeniyle alternatif ma- teryal arayışına girilmiştir. ${ }^{26}$ Son yıllarda bitki bazlı alternatifler yüksek biyouyumluluk, iyi antimikrobiyal aktivite, maaliyet etkisi, raf ömrü uzunluğu nedeniyle popüler hale gelmiştir.

Önçağ ve ark, üç kanal içi medikamentin ve propolisin Enterococcus faecalis'e karşı etkinliğini değerlendirmiș; kanal içi medikament olarak propolisin E. faecalis'in büyümesini ve çoğalmasını önlediğini, uygun antibakteriyel etkinliğe sahip olduğunu bildirmişlerdir. ${ }^{27}$

Peganium harmala tohumlarında ve köklerinde bulunan alkoloidlerin antienflamatuar, antiprotozoal, antibakteriyel, antifungal etkileri bulunmaktadır. ${ }^{28}$ Yapılan bir in vitro çalışmada Peganium harmala tohum ekstresinin antimikrobiyal kapasitesi (MIC) ve sitotoksik etkileri \%5,25'lik konsantrasyonda hazırlanan $\mathrm{NaOCl}$ ile kıyaslanmıştır. Çalışmanın sonucunda gruplar arasında istatistiksel olarak anlamlı bir fark bulunmamıştır. ${ }^{29}$

2013 yılında yapılan in vitro bir çalışmada 30 adet tek köklü çekilmiş dişler üzerinde papatya özünün "mixture of tetracycline asid and detergant" (MTAD) ve \%2,5 $\mathrm{NaOCl}$ ile smear tabakası kaldırma etkinliklerini karşılaştırılmıştır. MTAD kullanılan grupta smear tabakasının tamamı kaldırılmışken, papatya özütü kullanılan grupta $\% 50$ 'den fazla dentin tübülleri açığa çıkmıştır. Papatya özütü \%2,5 NaOCI' den istatiksel olarak daha başarılı bulunmuştur. ${ }^{30}$

Kekik özü çözeltisi, 180 adet maksiller keser diş üzerindeki smear tabakasını kaldırma etkileri açısından değerlendirilmiștir. Çalıșmanın sonucunda farklı kekik özüt konsantrasyonlarının (\%5 ve \%2) smear tabakasını tek başına tamamen kaldıramadığını ancak \%17 etilen diamin tetra asetik asit (EDTA) ile birleştirildiğinde smear tabakasını dentin erozyonuna sebep olmadan kaldırdığı gözlenmiștir. ${ }^{31}$

Greyfurt, mandalina, lime ve limon yağlarının kök kanalı yenileme prosedürlerinde güta perka'yı çözme yeteneği araştırılmış ve bu etki kloroform ile karşılaștırılmıștır. Kloroformun en iyi çözücü olduğu, ardından sırasıyla greyfurt yağı, mandalina yağı, lime yağı ve limon yağı bașarılı bulunmuștur. ${ }^{32}$

\section{Cerrahi Kullanım}

Bitkisel kaynaklardan; diş hekimliği uygulamalarında çekim soketinin iyileştirilmesinde, antikoagülan ve analjezik etkileri nedeniyle yararlanılmaktadır. Yapılan bir klinik çalışmada, alveolar soket yara iyileşmesinde propolisin etkisini değerlendirmek amacıyla çekim tedavisi sonrası hastalara propolis alkollü ekstresi ile gargara yaptırılmıştır. Hastalar ameliyat$\tan 7,14,30$ ve 45 gün sonra geri çağrılmış; histolojik ve klinik muayenelere tabi tutulmuştur. Çalışmanın 
sonucunda ağız gargarasının yara iyileșmesini arttırdığı; antiinflamatuar ve analjezik etkiler gösterdiği bildirilmiştir. Eksfoliyatif sitolojik değerlendirmede ise cerrahi yaraların epitelize olduğu gözlemlenmiștir. $^{33} 2017$ yılında yapılan bir çalışmada atravmatik diş çekimi sonrası aloe vera emdirilmiş spongostanlar sokete yerleştirildiğinde, analjeziklere göre ağrı kontrolünde daha bașarılı olduğu gözlenmiștir. Ayrıca aloe veranın yara iyileşmesinde de etkili olduğu bildirilmiştir. $^{34}$

Isola ve ark. tarafından yapılan bir çalışmada mandibular üçüncü molarları cerrahi olarak çekilmesi gereken 82 hasta rastgele olarak kontrol grubu, ibuprofen grubu ve bir fitoterapötik ilaç (baicalin, $190 \mathrm{mg}$; bromelain, $50 \mathrm{mg}$; escin, $30 \mathrm{mg}$ ) grubu olmak üzere ayrılmıştır. Çalışmanın sonucunda gruplar arasında istatistiksel olarak benzer sonuçlar elde edilmiștir. ${ }^{35}$

Cerrahi uygulamalarda antikoagülan etkisinden yararlanmak amaciyla Ankaferd Blood Stopper® (ABS) kullanılmaktadır. ABS; Thymus vulgaris, Glycyrrhiza glabra, Vitis vinifera, Alpinia officinarum ve Urtica dioica'dan meydana gelen tıbbi bitki özütüdür. Baykul ve ark. cerrahi diş çekimi sonrası hemorajik diyatezi olan hastaların kanama kontrolünde $\mathrm{ABS}^{\prime}$ in 10$20 \mathrm{dk}$. içerisinde etkili olduğunu gözlemlemişlerdir. ${ }^{36}$

\section{Çeşitli Uygulamalar}

Fitoterapiden diş hekimliğinde yara iyileşmesinde, ağız içi lezyonların ve dentin hipersensitivitesinin tedavisinde de yararlanılmaktadır. Bunların yanı sıra bitkisel ekstreler avülse dişlerin saklanmasında uygun bir ortam olarak da kullanılmaktadır.

Duarte ve ark. Matricaria chamomile bitkisinin (papatya) sıçanlarda oral ülser tedavisi üzerindeki etkisini araştırmıştır. Papatya ile tedavi edilen hayvanlar, 10 gün sonra epitelizasyon ve kollajen lif yüzdesi açısından en iyi sonuçları göstermiștir. ${ }^{37}$ Hosseini ve ark. oral liken planus (OLP) tedavisinde semizotunun etkilerini değerlendirmiștir. Semizotu hastaların yaklaşık \%83'ünde kısmi ile tam klinik iyileşme sağlarken, \%17'sinde herhangi bir değisşiklik yaratmamıştır. Bu bulgulara göre semizotu OLP tedavisinde klinik olarak etkili bulunmuştur. ${ }^{38} 2012$ yllında yapılan bir çalışmada propolis tabletlerinin tekrarlayan aftöz ülser oluşumu ve sayısı üzerine etkisini değerlendirmişlerdir. Çalışma sonucunda aftöz ülser oluşumunda azalma sağladığı gözlemlenmiştir. Propolis, yara üzerinde ülser tahrişini önleyen ve aynı zamanda anestezik ve antienflamatuar etkiler sağlayan yapışkan koruyucu bir tabaka olușturmuștur. Öte yandan, propolisin bağıșıklık sistemini uyardığı ve lezyonların nüksetmesini etkili bir şekilde azalttığ gözlenmiștir. ${ }^{39}$

Propolis ayrıca çekilmiş dişler için uygun bir sakla- ma ortamıdır. Al-Shaher ve ark. propolis ve $\mathrm{Ca}(\mathrm{OH})_{2}$ tozuna maruz kalan PDL ve dental pulpa fibroblastlarının canlılığını karșılaștırmışlardır. $4 \mathrm{mg} / \mathrm{mL}$ veya daha düşük propolis konsantrasyonlarına maruz kalan PDL ve dental pulpa fibroblastlarının \%75'inin canlı kaldığı; buna karşılık $4 \mathrm{mg} / \mathrm{mL} \mathrm{Ca}(\mathrm{OH})_{2}$ hücreler için sitotoksik bulunmuștur. Bu konsantrasyona maruz kalan hücrelerin \%25'inden azı hayatta kalmiștır. $^{40}$

\section{SONUÇ}

Geçmişten günümüze kadar tıbbın neredeyse her alanında fitoterapiden yararlanılmış; halen de yararlanılmaya devam edilmektedir. Buna rağmen; nispeten az sayıda bitki türü için araştırmalar yapılmış ve medikal kullanımı için olanak sağlanmıștır. Günümüzde ise doğal ve alternatif tedavilere eğilimin artması ile fitoterapi tekrar popülerlik kazanmıştır. Bitkisel ekstrelerin konvansiyonel ilaçlara göre yan etkilerinin az olması, ekonomik ve ulaşılabilir olmaları dental tedavilerde de kullanımlarını yaygınlaştırmıştır. Literatür incelendiğinde bitkilerin antiinflamatuar, antibakteriyel, analjezik ve sedatif gibi özellikleri nedeniyle dental tedavilerde kullanıldığı pek çok in vitro çalışma bulunabilir. Ancak öngörülemeyen toksik etkiler ve istenmeyen ilaç etkileşimlerini önlemek amacıyla daha çok klinik araştırmaya ihtiyaç vardır.

\section{KAYNAKLAR}

1. Hotwani K, Baliga S, Sharma K. Phytodentistry: use of medicinal plants. J Complement Integr Med. 2014 Dec;11:233-51.

2. Sert E, Sert A, Kalaycı MZ, Sakarya AA, Yüksel ŞB. Ağız ve diș sağlığı'nda fitoterapinin yeri. Integr Tıp Derg 2015; 3: 35-40.

3. Gurib-Fakim A. Medicinal plants: traditions of yesterday and drugs of tomorrow. Mol Aspect Med 2006;27:1-93.

4. Özen T, Güzdüz K, Aksever H, Karaçaylı Ü. Diş Hekimliğinde Fitoterapi. Turkiye Klinikleri J Dental Sci 2011;17.

5. Park YK, Alencar SM, Aguiar CL. Botanical origin and chemical composition of Brazilian propolis. Journal of Agricultural and Food Chemistry. 2002;50:2502-6.

6. Parolia A, Kundabala M, Rao NN, Acharya SR, Agrawal $\mathrm{P}$, Mohan M, et al. A comparative histological analysis of human pulp following direct pulp capping with propolis, mineral trioxide aggregate and dycal. Aust Dent J 2010;55:59-64.

7. Pistorius A, Willershausen B, Steinmeier EM, Kreislert M. Efficacy of subgingival irrigation using herbal extracts on gingival inflammation. J Periodontol 2003;74:616-22. 
8. Shahnaz HA, Hifza A, et al. Lipid studies of Cuminum cyminum fixed oil. Pak J Bot 2004 Apr;36:395-402.

9. Pappas PG, Rex JH, et al. Guidelines for treatment of candidiasis. Clin Infect Dis 2004;38:161-189.

10. Khorram Z, Hakimaneh SM, Naeini A, Rafieinezhad R, Salari AM, Shayegh SS. The Antifungal Effects of Two Herbal Essences in Comparison with Nystatin on the Candida Strains Isolated from the Edentulous Patients. J Contemp Dent Pract. 2019;20:716-719.

11. Noumi E, Snoussi M, Hajlaoui H, Valentin E, Bakhrouf A. Antifungal properties of Salvadora persica and Juglans regia L. extracts against oral Candida strains. Eur J Clin Microbiol Infect Dis. 2010;29:81-88.

12. Jayaprakash K, Veeresha KL, Hiremath SS. A comparative study of two mouthrinses on plaque and gingivitis in school children in the age group of 13-16 years in Bangalore city. J Indian Soc Pedod Prev Dent 2007 Jul-Sep;25:126-129.

13. Kamath NP, Tandon S, Nayak R, Naidu S, Anand PS, Kamath YS. The effect of aloe vera and tea tree oil mouthwashes on the oral health of school children. Eur Arch Paediatr Dent. 2020;21:61-66.

14. Nakao R, Senpuku H, Ohnishi M, Takai H, Ogata Y. Effect of topical administration of propolis in chronic periodontitis. Odontology. 2020;108:704-714.

15. Thomas B, Y Shetty S, Vasudeva A, Shetty V. Comparative evaluation of Antimicrobial Activity of Triphala and commercially available Toothpastes: An invitro study. International Journal of Public Health Dentistry $2011 ; 2: 8-12$.

16. Bhattacharjee R, Nekkanti S, Kumar NG, Kapuria K, Acharya S, Pentapati KC. Efficacy of triphala mouth rinse (aqueous extracts) on dental plaque and gingivitis in children. J Investig Clin Dent. 2015;6:206-210.

17. Velazquez C, Navarro M, Acosta A, Angulo A, Dominguez Z, Robles R, et al. Antibacterial and free-radical scavenging activities of Sonoran propolis. Journal of Applied Microbiology. 2007; 103:1747-56.

18. Armidin RP, Yanti GN. Effectiveness of Rinsing Black Tea Compared to Green Tea in Decreasing Streptococcus mutans. Open Access Maced J Med Sci. 2019;7:3799-3802. Published 2019 Nov 14.

19. Merkle HP, Higuchi WI. Effects of antibacterial microenvironment on in vitro plaque formation of Streptococcus mutans as observed by scanning electron microscopy. Arzneimittelforschung. 1980;30:1841-1846.

20. Hong SJ, Jeong SS, Song KB. Effects of sanguinaria in fluoride-containing dentifrices on the remineralisation of subsurface carious lesion in vitro. Int Dent J 2005;55:128-32.

21. Sela MN, Steinberg D, Segal R. Inhibition of the activity of glucosyltransferase from Streptococcus mutans by glycyrrhizin. Oral Microbiol Immunol 1987;2:125128.
22. Peters MC, Tallman JA, Braun TM, Jacobson JJ. Clinical reduction of $\mathrm{S}$. mutans in pre-school children using a novel liquorice root extract lollipop: a pilot study. Eur Arch Paediatr Dent. 2010;11:274-278.

23. Kamat S, Rajeev K, Prahlad S. Role of herbs in endodontics: An update. Endodontology 2011;23:96-100.

24. Wheatley D. Medicinal plants for insomnia: a review of their pharmacology, efficacy and tolerability. J Psychopharmacol 2005;19:41421.

25. Franz-Montan M, Motta RH, de Andrade ED. Use of phytotherapy in dentistry. Phytother Res 2008;22:9938.

26. Murray PE, Farber RM, Namerow KN, Kuttler S, Garcia-Godoy F. Evaluation of Morinda citrifolia as an endodontic irrigant. J Endod. 2008;34:66-70.

27. Oncag O, Cogulu D, Uzel A, Sorkun K. Efficacy of propolis as an intracanal medicament against Enterococcus faecalis. General dentistry. 2006;54:319-22.

28. Moloudizargari M, Mikaili P, Aghajanshakeri S, Asghari MH, Shayegh J. Pharmacological and therapeutic effects of Peganum harmala and its main alkaloids. Pharmacogn Rev. 2013;7:199-212.

29. Tabrizizadeh M, Kazemipoor M, Hakimian M, et al. Effects of a Peganum harmala (Zygophyllaceae) preparation for root canal disinfection. Phytother Res. 2018;32:672-677.

30. Venkataram V, Gokhale ST, Kenchappa M, Nagarajappa R. Effectiveness of chamomile (Matricaria recutita L.), MTAD and sodium hypochlorite irrigants on smear layer. Eur Arch Paediatr Dent. 2013;14:247-252.

31. Ok E, Adanir N, Ozturk T. Antibacterial and smear layer removal capability of oregano extract solution. Eur J Dent 2015; 9: 20-24.

32. Jantarat J, Malhotra W, Sutimuntanakul S. Efficacy of grapefruit, tangerine, lime, and lemon oils as solvents for softening gutta-percha in root canal retreatment procedures. J Investig Clin Dent 2013; 4: 60-63.

33. Magro Filho 0, de Carvalho AC. Application of propolis to dental sockets and skin wounds. J Nihon Univ Sch Dent. 1990 Mar;32:4-13.

34. Nimma VL, Talla HV, Bairi JK, Gopaldas M, Bathula H, Vangdoth S. Holistic Healing Through Herbs: Effectiveness of Aloe Vera on Post Extraction Socket Healing. J Clin Diagn Res. 2017;11:ZC83-ZC86.

35. Isola G, Matarese M, Ramaglia L, Iorio-Siciliano V, Cordasco G, Matarese G. Efficacy of a drug composed of herbal extracts on postoperative discomfort after surgical removal of impacted mandibular third molar: a randomized, triple-blind, controlled clinical trial. Clin Oral Investig. 2019;23:2443-2453.

36. Baykul T, Alanoglu E, Kocer G. Use of ankaferd blood stopper as a hemostatic agent: a clinical experience. J Contemp Dent Pract 2010;11:E088-94. 
37. Duarte CM, Quirino MR, Patrocínio MC, Anbinder AL. Effects of Chamomilla recutita (L.) on oral wound healing in rats. Med Oral Patol Oral Cir Bucal 2011;16:e716-21.

38. Agha-Hosseini F, Borhan-Mojabi K, Monsef-Esfahani HR, Mirzaii-Dizgah I, Etemad-Moghadam S, Karagah A. Efficacy of purslane in the treatment of oral lichen planus. Phytother Res. 2010 Feb;24:240-4.
39. Sulaiman GM, Ad'hiah AH, Al-Sammarrae KW, Bagnati R, Frapolli R, Bello E, et al. Assessing the anti-tumour properties of Iraqi propolis in vitro and in vivo. Food and chemical toxicology. 2012;50:1632-41.

40. Al-Shaher A, Wallace J, Agarwal S, Bretz W, Baugh D. Effect of propolis on human fibroblasts from the pulp and periodontal ligament. Journal of endodontics. 2004;30:359-61. 